\title{
Deniz Boru Hattı Dinamik Davranışının Sonlu Elemanlar Yöntemi ile Analizi
}

\author{
Begüm Yurdanur DAĞLI"1 ${ }^{*}$, Dilay UNCU² ${ }^{\oplus}$, Yeşim TUSKAN $^{3} \oplus$ \\ ${ }^{1}$ Manisa Celal Bayar Üniversitesi, Teknik Bilimler Meslek Yüksekokulu, İnşaat.Bölümü, 45140, Manisa,Türkiye \\ 2,3Manisa Celal Bayar Üniversitesi, Mühendislik Fakültesi, İnşaat Mühendisliği Bölümü, 45140, Manisa,Türkiye
}

(Alınış / Received: 10.12.2018, Kabul / Accepted: 27.05.2019, Online Yayınlanma / Published Online: 30.08.2019)

\section{Anahtar Kelimeler}

Hidrodinamik kuvvet,

Sonlu elemanlar yöntemi,

Stokes 3. mertebe dalga teorisi
Özet: $\mathrm{Bu}$ çalışmada hidrodinamik kuvvetlere maruz kalan deniz boru hattının dinamik davranıșı Sonlu Elemanlar Yöntemi kullanılarak incelenmiștir. Dalga parametreleri Stokes 3. Mertebe Dalga Teorisi kullanılarak hesaplanmıştır. Dalga periyodu boyunca değișen sürükleme, atalet ve kaldırma kuvvetleri Morison Denklemi ile belirlenmiştir. Zaman Tanım Alanında Analiz yaklaşımı dikkate alınarak bir önceki kuvvet nedeni ile deforme olan sistem üzerine yeni yükleme yapılmıştır. Sonlu Elemanlar Yöntemi ile periyot süresince kritik kesit deplasman değerleri hesaplanmıștır. Elde dilen maksimum deplasmanlar, akıș analizini yapısal analiz ile birleștiren ANSYS-FSI (Fluid Structure Interaction) tekniği ile belirlenen değerler ile karşılaştırılmıştır. İki analize ilişsin sonuçların tutarlı olması Sonlu Elemanlar Yönteminin eş değer dinamik analiz yapmak için kullanılabileceğini göstermektedir.

\section{Analysis of Dynamic Behaviour of Marine Pipelines with Finite Elements Method}

\section{Keywords}

Hydrodynamic forces, Finite elements method, $3^{\text {rd }}$ order Stokes wave theory

\begin{abstract}
In this study, the dynamic behaviour of the marine pipeline subjected to hydrodynamic forces are investigated by using the Finite Element Method. Wave parameters are calculated using Stokes $3^{\text {rd }}$ Order Wave Theory. The drag, inertia, and lifting forces that changed during the wave period are determined by the Morrison Equation. The new loading is performed on the system which is deformed due to the previous force considering Time History approach. The critical values of section displacements are calculated by using the Finite Element Method. The maximum displacements are compared with those determined by ANSYS-FSI (Fluid Structure Interaction) technique which combines structural analysis with flow analysis. The concordance of the results of the two analysis methods indicates that the Finite Element Method can be used to perform an equivalent dynamic analysis.
\end{abstract}

\section{Giriş}

Doğalgaz, su, petrol iletimi başta olmak üzere günümüzde yaygın olarak kullanılan sualtı boru hatları deniz deşarj sistemleri, endüstriyel tesis soğutma suyu temini, enerji-haberleşme kablolarının deniz geçişi gibi daha birçok alanda önemli çözümler sunmaktadır. Topografik, hidrografik, jeoteknik, oşinografik araştırmalar gibi kapsamlı aşamaları olan boru hattı tasarımının amacı işletme ve bakım masraflarını en aza indirecek güzergah ve stabil boru kesitini belirlemektir. Bu așamada yapının belirlenen ekonomik ömrünü tamamlayabilmesi ancak dalga ve /veya akıntı kökenli çevresel kuvvetlerin göz önünde bulundurulduğu dinamik hesapların yapılması ile mümkündür. Silindir etrafındaki salınımlı akım alanına ilişkin ilk çalışmalar Sarpkaya ve Rajobi [1],
Lundgren vd. [2], Sümer vd. [3] tarafından yapılmıştır. $\mathrm{Bu}$ çalışmalar hidrodinamik kuvvetlerin Reynolds sayısına (Re), Keulegan-Carpenter sayısına (KC) ve açıklık oranına $(e / D, e$ : silindir ile taban arasındaki mesafe, $D$ : daire çapı) bağlı olarak değiştiğini göstermiştir. Re sayısının artışı ile akım kompleks hale gelmekte, $K C$ sayısının artışı ile atalet kuvvetlerinin hakimiyeti de artmaktadır. Daha sonra deniz boru hatları üzerine yapılan araştırmalarda ise farklı koşullar altında, yapı-akışkan ve zemin etkileşimleri konu alınmıștır. Ballet ve Hobbs [4] boru hattında taşınan sıvılar ile deniz suyu arasındaki yoğunluk ve ıSı farkı etkisinin oluşturduğu kuvvetleri araştırmışlardır. Bu kuvvetler kritik sıcaklık ile ilişkilendirilen asimetrik ve simetrik yapıda burkulmaya sebep olmaktadır. Xiaoyun vd. [5] dalga, zemin ve boru etkileşimini deneysel olarak 
incelemişlerdir. Dalga hareketi nedeni ile doğrultusu periyodik olarak değişen su partikülünün hareketini simüle eden düzenek ile testler gerçekleștirilmiştir. Boru ağırlığı ve hidrodinamik parametreler arasındaki ilişki boyutsuz analizler ile incelenmiştir. Borunun başlangıç gömülme derinliğinin boru stabilitesi üzerindeki etkisi ortaya konulmuştur. Ong vd. [6] iki boyutlu $\mathrm{k}-\varepsilon$ türbülans modelini kullanarak deniz tabanına yakın silindir etrafındaki akımı incelemişlerdir. Reynolds sayısının farklı değerleri için yapılan çalışma ile silindir ve deniz tabanı arasındaki mesafenin etkisi ortaya konulmuştur. Sediment taşınımının silindir, taban arasındaki mesafenin azalması ile arttığı görülmüştür. Draper vd. [7] büyük fırtınaların sebep olduğu yorucu meteorolojik ve oşinografik şartlar altında boru hattının stabilitesini araştırmışlardır. Dalga ve akıntı hızının artması ile deniz tabanına oturan boru hattının altında oyulmalar meydana gelmekte bu da boru hattının dinamik davranışını etkilemekte, salınıma sebep olmaktadır. Boru hattının bașlangıç pozisyonu ve akıșkan partikülünün ivmesi ile değișen oyulma derinliği özellikle petrol, gaz taşıyan hatlar ve elektrik şebekeleri açısından büyük önem taşımaktadır. Hidrodinamik kuvvetlerin farklı yöntemler ile belirlenmesi de önemli bir araştırma konusudur. Gökkuş [8] çalışmasında boru hatlarını projelendirirken bilgisayar destekli tasarımın gerekliliğinden bahsetmiştir. Dalgaların istatistiksel analizini ve stabilite hesabını belirlemek amacı ile kendi yazdığı programı kullanmıştır. Varol ve Gökkuş [9] dalga kökenli dinamik kuvvetleri tesir çizgisi yöntemi ile hesaplamışlardır. Kuvvetlerin periyot boyunca değişimi, dalga geliş açısının $45^{0}$ olduğu koşullar altında incelenmiştir. Eksenel dalga kuvvetlerinin boru hattı üzerinde belirli aralıklarda basınç belirli aralıklarda da çekme etkisi oluşturduğu görülmüştür. Cokgör ve $\mathrm{Avcl}$, laboratuardaki açık kanalda, akım ve dalganın birlikte bulunması halinde, tabana oturan ve tabana kısmen gömülü silindirik borulara etkiyen hidrodinamik kuvvetler ve bu kuvvetlerle ilgili parametreleri deneysel olarak araştırmışlardır [10]. Tek silindir dikkate alınarak yapılan gözlemler sürükleme kuvveti ve kaldırma kuvveti katsayılarının gömülme oranı ile azaldığını göstermiştir. Çift silindir olması durumunda kuvvet katsayıları ve gömülme oranı arasındaki ilişki değişmemektedir.

$\mathrm{Bu}$ çalışma kapsamında askıdaki deniz boru hattı üzerinde oluşan deplasmanlar iki farklı yöntem ile hesaplanmiştır. Hidrodinamik kuvvet parametrelerinin hesaplarında yaygın olarak kullanılan Lineer Dalga Teorisinin aksine akışkan partikülüne ait hız ve ivme bileşenleri Stokes 3 . Mertebe Dalga Teorisi yardımıyla belirlenmiştir. Alternatif çözüm metodu olarak ileri sürülen tekrarlı analizler ile deplasman hesabı, lokal rijitlik matrisinin 1sn olarak belirlenen tanım aralıklarında değişkenlik göstermesine bağlı olarak Sonlu Elemanlar Yöntemi ile gerçekleştirilmiştir. Uygulanan eşdeğer dinamik analiz yönteminin geçerliliği ANSYS-FSI (Fluid
Structure Interaction) tekniği kullanılarak kontrol edilmiştir.

\section{Deniz Boru Hattı Yapısal Tasarımı}

Şekil 1'de verilen homojen ve üniform malzemeden olușan boru hattı $25 \mathrm{~m}$ 'de bir kullanılan $0.5 \mathrm{~m}$ yüksekliğinde Elastisite modülü $32 \times 10^{7} \mathrm{kN} / \mathrm{m}^{2}$, Poisson oranı 0.2 olan beton tespit kitleleri ile askıda kalacak şekilde deniz tabanına sabitlenmiştir. Boru hattı ile deniz tabanı arasındaki mesafe $0.2 \mathrm{~m}$ alınarak sabit kabul edilmiştir. Dış çapı $1 \mathrm{~m}$, et kalınlığı $0.01 \mathrm{~m}$ olan boru, Elastisite modülü $21 \times 10^{7} \mathrm{kN} / \mathrm{m}^{2}$, Poisson oranı 0.3 ve yoğunluğu $78.50 \mathrm{kN} / \mathrm{m}^{3}$ olan çelik kullanılarak tasarlanmıştır. Çelik için, malzemenin Prandtl - Reuss akış kuralı ve Von Mises verim kriteri ile uyumlu olacağı varsayılmaktadır [11]. Borunun kendi ağırlığı nedeni ile oluşacak deplasmanlar ihmal edilmiştir.

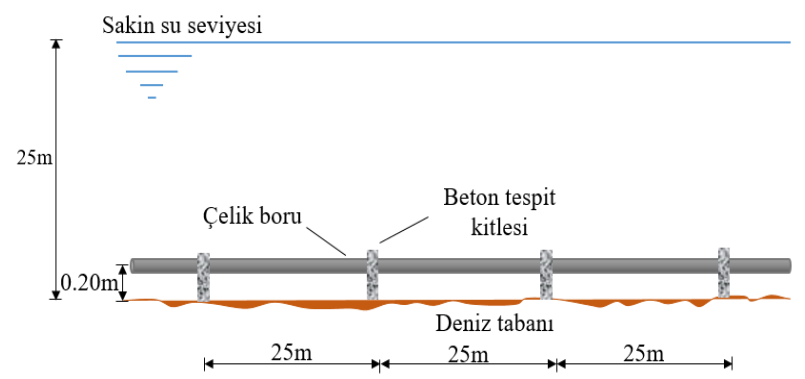

Şekil 1. Deniz boru hattı modeli

\section{Deniz Boru Hattına Etkiyen Hidrodinamik Kuvvetler}

Deniz yapılarının stabilitesini etkileyen en önemli çevresel faktörlerden biri olan dalgaya ilişkin başlıca parametreler dalga yüksekliği $H$, dalga boyu $L$ ve dalga periyodundan $T$ oluşmaktadır $[12,13]$. Ayrıca, farklı çevresel koşullar, dalga teorilerini belirlemek için kullanılan su derinliği ile karakterize edilmektedir [14]. Dalga karakteristikleri sinüs dalgası üzerinde Şekil 2'de gösterilmiştir.

Bu çalıșmada açık deniz koşulları Stokes 3. Mertebe Dalga Teorisi kullanılarak modellenmiștir. Boru hattı stabilite analizinin daha olumsuz koşullar altında incelenmesi amacı ile uygulanan Stokes 3. Mertebe Dalga Teorisi, dalga tepesi ve çukuru arasındaki asimetri ile kütle taşınımını göz önünde bulundurduğundan elde edilen akışkan partikülü hızları ve buna bağlı hesaplanan hidrodinamik kuvvet bileşeni değerleri de artmaktadır.

Le Méhauté [15] tarafından tanımlanan dalga teorilerinin geçerlilik sinırları dikkate alınarak, $\mathrm{H}=6.0 \mathrm{~m}, \mathrm{~T}=6 \mathrm{~s}$, ve $\mathrm{d}=25 \mathrm{~m}$ olarak kabul edilmiştir. Dalga boyu $L$ ise derinlik (d), genlik (a) ve dalga sayısına ( $k$ ) bağlı Denklem [1] ile $70.65 \mathrm{~m}$ olarak hesaplanmiştır. 


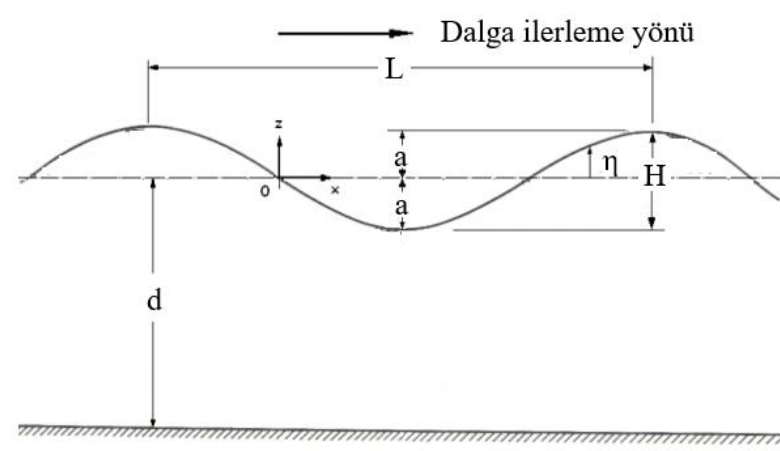

Şekil 2. Dalga karakteristikleri

$L=\frac{g T^{2}}{2 \pi} \tanh k d\left[1+\left(\frac{2 \pi a}{L}\right) \cdot \frac{5+2 \cosh 2 k d+2 \cosh ^{2} 2 k d}{8 \sinh ^{4} k d}\right]$

Denizsuyu karakteristik özelliklerinden yoğunluk $(\rho)$ $1025 \mathrm{~kg} / \mathrm{m}^{3}$, dinamik viskozite $(\mu)$ ise $0.0015 \mathrm{Ns} / \mathrm{m}^{2}$ olarak alınarak hesaplarda kullanılmıştır. Kritik dalga dikliği așılmadı̆̆ı için kabul edilen koșullar altında dalga kırılması meydana gelmemektedir. Dalganın deniz boru hattına 900'lik açı ile geldiği göz önünde bulundurularak elde edilen su yüzü profili Şekil 3'de verilmiștir.

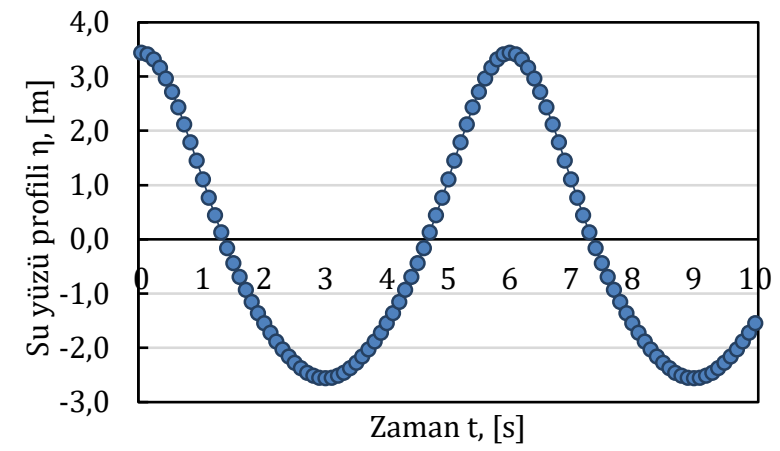

Şekil 3. Su yüzü profili

Hidrodinamik kuvvet hesabında kullanılan yörüngesel harekete sahip akıșkan partikülünün yatay hız bileșeni $u$ ve düşey hız bileşeni $v$, Denklem [2] ve [3] ile tanımlanmıştır.

$$
\begin{gathered}
u=c\left(\begin{array}{c}
F_{1} \cdot \cosh k S \cdot \cos \theta+F_{2} \cdot \cosh 2 k S \cdot \cos 2 \theta \\
+F_{3} \cdot \cosh 3 k S \cdot \cos \theta
\end{array}\right) \\
v=c\left(\begin{array}{c}
F_{1} \cdot \sinh k S \cdot \sin \theta+F_{2} \cdot \sinh 2 k S \cdot \sin 2 \theta \\
+F_{3} \cdot \sinh 3 k S \cdot \sin \theta
\end{array}\right)
\end{gathered}
$$

Burada su yüzü profili ile sakin su seviyesi arasındaki mesafe $z$ ile gösterildiğinde $S=d+z$ ve dalga yayılma hızı $c=L / T$ bağıntısı yardımıyla hesaplanmaktadır. Dalga sayısı $k$, faz açısı $\theta$ ile verilmiştir. Denklemde kullanılan $F_{n}$ sabitleri ise derinlik $(d)$, genlik (a) ve dalga sayısına $(k)$ bağlı olarak aşağıdaki gibi hesaplanır [16].

$$
\begin{gathered}
F_{1}=\frac{k a}{\sin k d}-(k a)^{2} \cdot \frac{\cosh ^{2} k d \cdot\left(1+5 \cosh ^{2} k d\right)}{8 \sinh ^{5} k d} \\
F_{2}=\frac{3}{4}(k a)^{2} \cdot \frac{1}{\sinh ^{4} k d}
\end{gathered}
$$

$$
F_{3}=\frac{3}{64}(k a)^{3} \cdot \frac{11-2 \cosh 2 k d}{\sinh ^{7} k d}
$$

Dalganın periyodik salınımı nedeni ile boru hattı etrafında oluşan sürükleme $F_{D}$ ve atalet $F_{I}$ kuvvetlerini kapsayan toplam yanal kuvvet $F_{H}$ Morison Denklemi ile

$$
F_{H}=\frac{1}{2} C_{d} \cdot \rho \cdot u \cdot|u|+C_{M} \cdot \rho \cdot \frac{\pi \cdot D^{2}}{4} \cdot \dot{u}
$$

şeklinde hesaplanmaktadır. Bağıntıda kullanılan $u^{\prime}$ akımın ivmesini, $\rho$ deniz suyunun yoğunluğunu, $D$ silindirik yapının çapını göstermektedir. Ele alınan model için $D / L$ oranı 0.2 değerinin altında kalmaktadır. Boru hattı çapına göre akışkan partiküllerinin yapmış olduğu yörüngesel hareketin rölatif olarak önemini ifade eden Keulegan and Carpenter $K C(u T / L)$ sayısı 15.4 olarak hesaplanmış ve Reynolds sayısı $(\rho u D / \mu), \quad R_{\mathrm{e}}>1.5 .10^{6} \quad$ olarak belirlenmiştir. Bu sınır değerler altında hidrodinamik atalet kuvveti katsayısı $C_{M}$ ve hidrodinamik sürükleme kuvveti katsayısı $C_{D}$ sırası ile 2.0 ve 1.0 olarak alınmıştır $[17,18]$.

Ayrıca tabana yakın yerleştirilen askıdaki boru hatları atalet ve sürükleme kuvvetlerine ilave olarak kaldırma $F_{L}$ kuvvetine de maruz kalmaktadırlar [18].

$$
F_{L}=\frac{1}{2} C_{L} \cdot \rho \cdot D \cdot u^{2}
$$

Burada $C_{L}$ hidrodinamik kaldırma kuvveti katsayısını göstermektedir ve 0.95 olarak kabul edilmiștir. Deniz boru hattına etkiyen yatay ve düşey hidrodinamik kuvvet bileşenlerinin zamana bağlı değişimi Tablo 1 'de verilmiștir. Bu değerler zaman aralığl $\Delta t=1 \mathrm{~s}$ alınarak dalga periyodu boyunca hesaplanmıştır.

Bağıntılar hız ve ivme terimlerini içerdiğinden, hız değiştikçe hidrodinamik kuvvetler de değişmektedir. Yatay hızlar dalga tepesi altında dalga yayılma doğrultusunda iken dalga çukuru altında dalga yayılma doğrultusunun tersinedir. $\mathrm{Bu}$ da yanal hidrodinamik kuvvetin belirli aralıklarda basınç (-) belirli aralıklarda da çekme ;(+) olarak etkimesine neden olmaktadır. Hidrodinamik kaldırma kuvveti ise deniz tabanından su yüzeyine doğru pozitif yönde etkimektedir.

Tablo 1. Hidrodinamik kuvvetler

\begin{tabular}{ccc}
\hline $\begin{array}{c}\text { Kuvvet } \\
(\mathrm{KN})\end{array}$ & $\mathrm{F}_{\mathrm{H}}$ & $\mathrm{F}_{\mathrm{L}}$ \\
\hline $\mathrm{t}=1 \mathrm{~s}$ & -31.55 & 8.55 \\
$\mathrm{t}=2 \mathrm{~s}$ & -36.77 & 5.93 \\
\hline $\mathrm{t}=3 \mathrm{~s}$ & -18.85 & 18.16 \\
$\mathrm{t}=4 \mathrm{~s}$ & 24.97 & 5.64 \\
\hline $\mathrm{t}=5 \mathrm{~s}$ & 50.03 & 9.18 \\
$\mathrm{t}=6 \mathrm{~s}$ & 57.91 & 55.94 \\
\hline
\end{tabular}


Tablo 1'de görüldüğü gibi dalga geliş açısının $90^{\circ}$ olması durumunda oluşan hidrodinamik kuvvetler $\mathrm{t}=6$ s anında en büyük değerlere ulaşmaktadır.

\section{Sonlu Elemanlar Yöntemi ile Analiz}

Mühendislik alanında yaygın olarak kullanılan Sonlu Elemanlar Yöntemi ile periyot boyunca değişen hidrodinamik kuvvetlerin ard arda sisteme yüklenmesi sonucu oluşan deplasman değerlerinin kombinasyonu hesaplanmıştır. Basit mesnet sınır koșullarına sahip 25m uzunluğundaki boru hattı 6 eșit parçaya bölünerek ayrıklaştırma yapılmıştır. Ele alınan boru hattı kesitinde açıklık boyunca oluşacak en büyük deplasman düğüm noktalarındaki değerler kullanılarak interpolasyon ile belirlenmiştir. Varyasyonel prensip ile düğüm noktalarındaki değerlerin belirlenmesi için kullanılan denklem takımının matris formundaki gösterimi

$$
[K]\{u\}=\{F\}
$$

şeklindedir. Burada, [K] global rijitlik matrisi, düğüm noktalarındaki bilinmeyenlerin sütun vektörü ve düğüm noktalarına uygulanmış olan dış kuvvetleri gösteren bir sütun vektörüdür. Global rijitlik matrisi Denklem [10]'da verildiği üzere [T] transformasyon matrisi, [k] lokal rijitlik matrisi ve $[T]^{-1}$ transformasyon matrisinin transpozesi ile hesaplanır.

$$
[K]=[T][k][T]^{-1}
$$

Elemanlar üzerinde oluşacak kesit reaksiyonları için pozitif kabul edilen yönler Şekil 4'de gösterilmiştir.

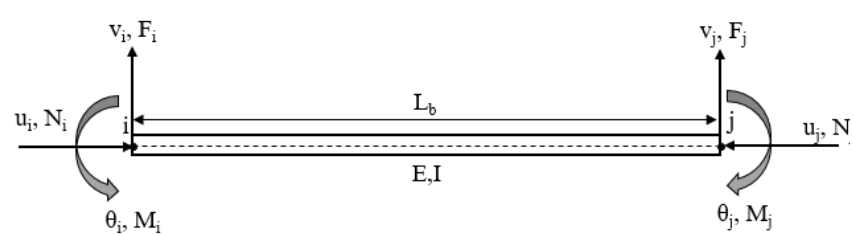

Şekil 4. Kesit reaksiyonları

Lokal rijitlik matrisi her elemanın kendi eksenindeki deplasman ve dönmeye karşı gösterdiği rijitliği ifade eder ve

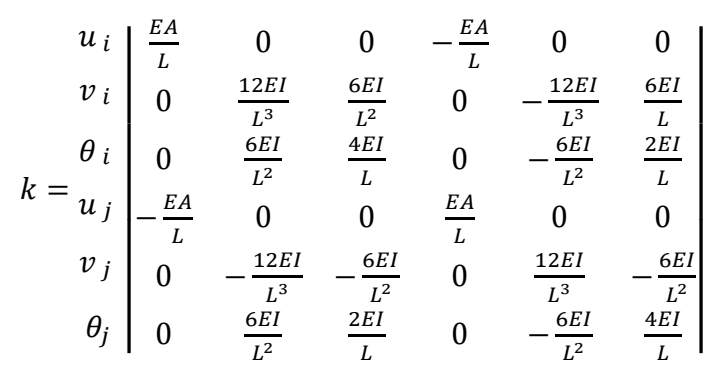

şeklinde gösterilir. Transformasyon matrisi ise

$$
T=\begin{array}{c|cccccc}
u_{i} & l & m & 0 & 0 & 0 & 0 \\
v_{i} & -m & l & 0 & 0 & 0 & 0 \\
\theta_{i} & 0 & 0 & 1 & 0 & 0 & 0 \\
u_{j} & 0 & 0 & 0 & l & m & 0 \\
v_{j} & 0 & 0 & 0 & -m & l & 0 \\
\theta_{j} & 0 & 0 & 0 & 0 & 0 & 1
\end{array} \mid
$$

olarak ifade edilir. Matris içeriğinde yer alan; $l$ ve $m$ terimleri elemanın yatay ve düşey eksen üzerindeki izdüşümleri olup, $l=\cos \theta, m=\sin \theta$ şeklinde gösterilir. Her bir eleman için oluşturulan global rijitlik matrisleri birleştirilerek noktaların birbirleriyle bağlantısı sağlanır ve sisteme ait global rijitlik matrisi elde edilir.

Yapısal sistemler üzerinde dış kuvvet etkisi ile oluşacak kesit reaksiyonlarının Sonlu Elemanlar Yöntemi ile hesabı statik çözüm vermektedir. Ancak dalga gibi periyodik olarak sisteme etkiyen kuvvetin her birim zaman içerisinde oluşturduğu deplasmanların bir sonraki yüklemede dikkate alınarak süperpoze edilmesi eş değer dinamik analiz olarak değerlendirilmektedir.

\section{ANSYS-FSI Analizi}

$\mathrm{Bu}$ çalıșma kapsamında deniz boru hattı dinamik analizi iki yönlü ANSYS-FSI tekniği ile bilgisayar destekli olarak gerçekleştirilmiştir. İki yönlü sistemde, akışkan hareketinin katı bir yapı üzerindeki etkisi belirlenerek oluşan tepki akışkan akışına aktarılmaktadır. Bu durum her bir zaman adımında iterasyon yapılarak akışkan-katı etkileşimi senkronize olana kadar sürdürülür $[19,20]$. Akışkanlar mekaniği denklemleri çözümü için Ansys-Fluent yazllımı kullanılırken, katı mekaniği hesaplamaları için Ansys Structural yazılımı kullanılmıştır. Bu çözücüler, Ansys Workbench ortamında FSI yöntemine uygun birleștirilmiştir. Şekil 5'de iki yönlü FSI analizine ilişkin akış şeması verilmiştir.

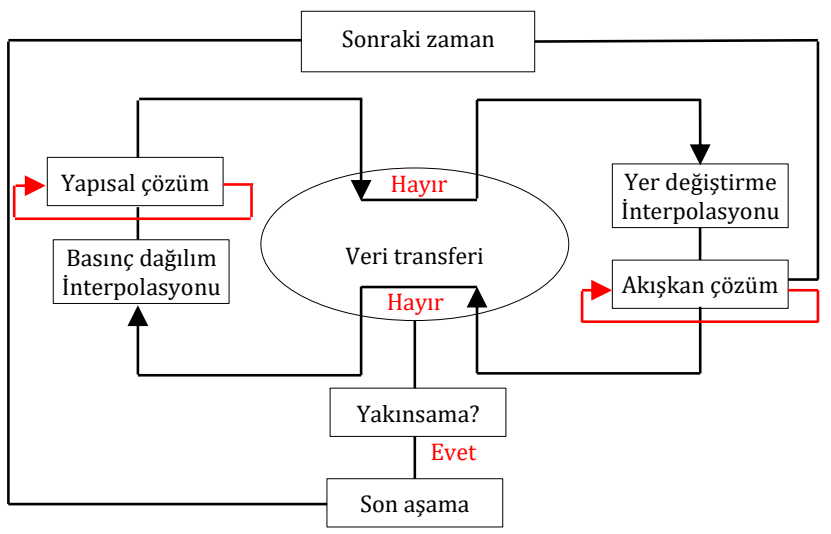

Şekil 5. İki yönlü FSI analizi akıș șeması

Çalışma kapsamında ANSYS Mechanical ile katı model ve ANSYS Fluent ile akışkan ortama ait hücre ağ yapısı, sınır şartları, analiz özellikleri ayrı ayrı tasarlanmıştır. Daha sonra boru hattına ait tüm yüzeyler akışkan-katı ara yüzeyi olarak seçilmiştir. Akışkan ortam $\mathrm{x}, \mathrm{y}, \mathrm{z}$ doğrultularında sırası ile 
$20 \times 28 \times 25$ m boyutlarında alınmıştır (Şekil 6). Boru hattı etrafında $5 \times 5 \times 25 \mathrm{~m}$ 'lik bölgede daha yoğun bir ağ yapısı oluşturulmuştur.

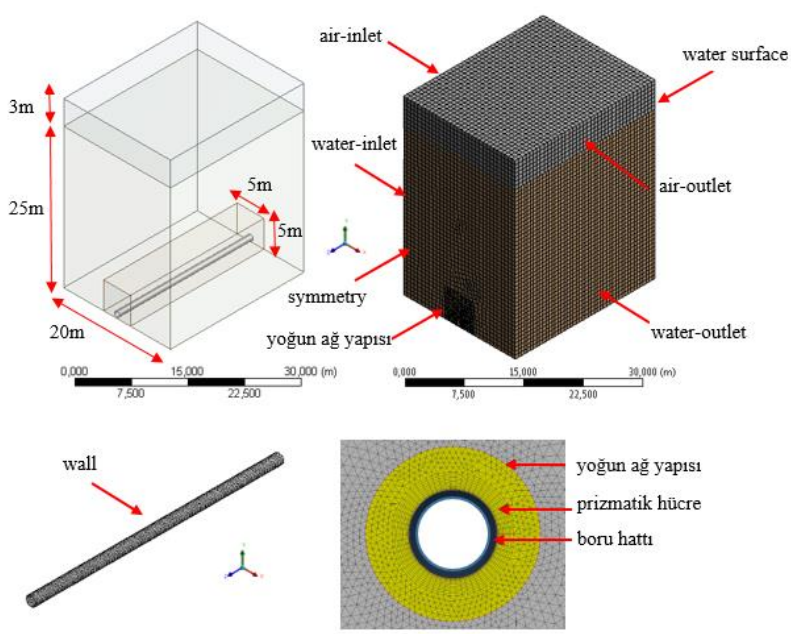

Şekil 6. Akışkan ortam geometrisi ve hücre ağı yapısı

Hekzahedral / prizmatik hücre ağı yapısı kullanılırken akışkan modeli için sıklaştırma yapılan bölgede ağ boyutu $0.01 \mathrm{~m}$ diğer bölgelerde ise $0.30 \mathrm{~m}$ kabul edilmiştir. Akışkan ve yapı etkileşiminin gerçekleştiği ara yüzde ise ağ boyutu $0.02 \mathrm{~m}$ 'dir. Boru hattı için sonlu elemanlar hücre ağ yapısı (CSM) kullanılmıştır. Akışkan ve katı ortam hücre sayısı yaklaşık olarak sırasıyla 1.15 milyon ve 42.000 olarak belirlenmiștir. Su yüzeyi ve hava arasındaki serbest yüzey EulerEuler yaklaşımına dayanan VOF (volume of fluid) formülasyonları ile tanımlanmıştır. Türbülans etkisi RANS (Reynolds-averaged Navier-Stokes) ile simüle edilmiş ve akışkan $\mathrm{k}-\varepsilon$ türbülans modeli ile tanımlanmıştır. Analizlerde açık zaman entegrasyonu kullanılmıștır. Boru hattını temsil eden katı modelin hareketi sabit-sabit mesnet sınır şartları dikkate alınarak gerçekleştirilmiştir. Deniz boru hattının ilk üç mod yapısı Şekil 7'de verilmiştir.

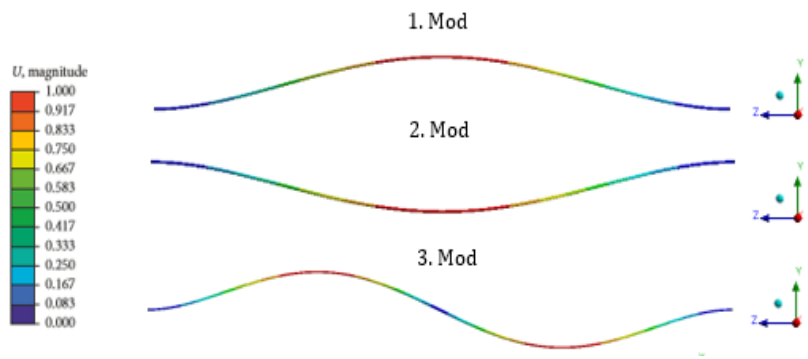

Şekil 7. Deniz boru hattı ilk üç mod şekli

Her iki çözücünün (ANSYS-Fluent ve ANSYSMechanical) nümerik koşullarını sekronize bir şekilde çözen System Coupling ile akışkan ve katı ara yüzünde basınç ve deplasman değerleri iki yönlü aktarılarak hesaplar yapılmıştır. Sistem, akış kuvvetlerindeki değişiklikler ve yapısal deplasmanlar öngörülen miktarın altına düşene kadar iteratif olarak çözülmüştür.

\section{Bulgular ve Tartışma}

Zamana bağlı değișen hidrodinamik kuvvetler altında Sonlu Elemanlar Yöntemi (SEY) ile iteratif çözüm yapılarak elde edilen deplasman değerleri bilgisayar destekli ANSYS-FSI analizi kullanılarak hesaplanan değerler ile karşılaştırılmıştır (Şekil 8). Değerlendirmeler akışkan partikülünün yörüngesel hareketini tamamladığı periyot boyunca (6s) incelenmiştir. Şekil 8'de görüldüğü gibi Sonlu Elemanlar Yöntemi ile elde edilen en büyük deplasman değeri $t=6 \mathrm{~s}$ anında $0.148 \mathrm{~m}$ olarak hesaplanmıştır. ANSYS-FSI analizinde ise bu değer $0.162 \mathrm{~m}$ olarak belirlenmiştir. İki yöntem arasındaki fark Denklem [13] ile hesaplanarak en fazla \%9.46 olarak ifade edilmiştir.

$$
\% \text { Fark }=\left|\frac{\omega_{A N S I S}-\omega_{S E Y}}{\omega_{S E Y}}\right| \times 100
$$

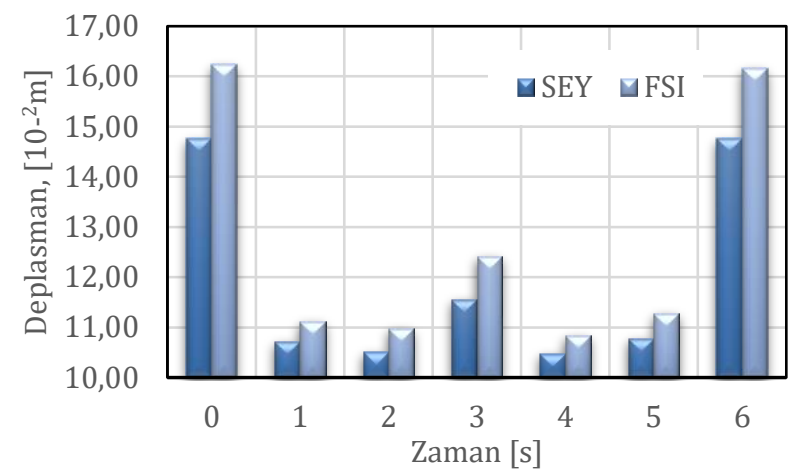

Şekil 8. En büyük deplasman değerleri

Boru hattı üzerindeki deplasmanlar incelendiğinde $\mathrm{t}=3 \mathrm{~s}$ anında elde edilen 0.105m'nin en küçük deplasman değeri olduğu görülmektedir. Ayrıca ANSYS-FSI analizi ile hesaplanan deplasman da bu zaman adımında $0.108 m^{\prime}$ dir. Aradaki fark \%1.03 olarak belirlenmiştir. Bu değer elde edilen en küçük yüzdelik fark değeridir. Hidrodinamik kuvvetler nedeni ile boru hattı üzerinde oluşan eğilme momenti $M$ değerleri

$$
E I v^{\prime \prime}(z)=M
$$

bağıntısı ile elde edilmiştir. Bağıntıda geçen $v$ boru hattında $z$ koordinat eksenine bağlı deplasmanı, $I$ atalet momentini, $E$ ise Elastisite modülünü ifade etmektedir. Toplam yanal hidrodinamik kuvvet $F_{H}$ ve düşey yönlü kaldırma kuvveti $F_{L}$ nedeni ile oluşan maksimum eğilme momentinin $\left(M_{H}\right.$ ve $\left.M_{L}\right)$ zaman ile değişimi Tablo 2'de ayrı ayrı verilmiştir.

Tablo 2'de görüldüğü gibi yanal hidrodinamik kuvvet etkisi, hidrodinamik kaldırma kuvveti etkisinden çok daha fazladır. Ayrıca akışkan partikülünün hareketine bağlı olarak baskın $M_{H}$ eğilme momenti değerleri 3s'den sonra negatif değerler alarak ters yönde deplasmana sebep olmaktadır. 
Tablo 2. Maksimum eğilme momenti değerleri

\begin{tabular}{ccc}
\hline Zaman & $\begin{array}{c}\text { Eğilme Momenti } \\
\mathrm{M}_{\mathrm{H}}(\text { KN.m) }\end{array}$ & $\begin{array}{c}\text { Eğilme Momenti } \\
\mathrm{M}_{\mathrm{L}}(\text { KN.m) }\end{array}$ \\
\hline $\mathrm{t}=1 \mathrm{~s}$ & 2333.42 & 592,34 \\
$\mathrm{t}=2 \mathrm{~s}$ & 2658.05 & 408.92 \\
\hline $\mathrm{t}=3 \mathrm{~s}$ & 1306.84 & 1258.91 \\
$\mathrm{t}=4 \mathrm{~s}$ & -1850.21 & 389.44 \\
\hline $\mathrm{t}=5 \mathrm{~s}$ & -3592.74 & 633.95 \\
$\mathrm{t}=6 \mathrm{~s}$ & -3974.25 & 3842.28 \\
\hline
\end{tabular}

\section{Sonuçlar}

$\mathrm{Bu}$ çalışmada deniz boru hatlarının stabilitesini belirleyen en önemli çevresel faktör olan dalga kökenli hidrodinamik kuvvetlerin etkisi Sonlu Elemanlar Yöntemi kullanılarak incelenmiştir. Sinüzoidal dalga hareketine maruz boru hattının, deniz tabanına gömülü olmayan 25m'si için yapılan hesaplarda Stokes 3. Mertebe Dalga Teorisi kullanılmıștır. Yanal hidrodinamik kuvveti oluşturan sürükleme ve atalet kuvvetleri ile düşey yönlü hidrodinamik kaldırma kuvveti değerleri Morison Denklemi ile belirlenmiştir. $\mathrm{Bu}$ kuvvetler altında yapının dinamik davranışı, dalga periyodu boyunca 1s zaman aralıkları dikkate alınarak deforme olmuş sistem üzerine global rijitlik matrisinin revize edilmesi ile gerçekleştirilen iteratif yüklemeler ile incelenmiştir.

Sonlu Elemanlar Yöntemi ile periyot süresince maksimum deplasman değerleri hesaplanmıştır. Sonuçların doğrulamasını yapmak amacı ile akış analizini yapısal analiz ile birleştiren iki yönlü ANSYSFSI (Fluid Structure Interaction) tekniği kullanılmıştır. ANSYS Mechanical ile katı model ve ANSYS Fluent ile akışkan ortam ayrı ayrı tasarlanmıştır. Daha sonra boru hattına ait tüm yüzeyler basınç ve deplasman aktarımının gerçekleştirildiği akışkan-katı ara yüzeyi olarak seçilmiştir. Sonuçlar karşılaştırılmış ve boru hattının en fazla deplasman yaptığı anda iki yöntem arasındaki farkın \%9.46 oranında olduğu görülmüştür. Deplasman değerlerinin azalması ile aradaki fark oranı da azalmıștır. $\mathrm{Bu}$ da Sonlu Elemanlar Yöntemi kullanılarak yapılan eș değer dinamik analizin alternatif bir yaklaşım olabileceğini göstermektedir.

\section{Kaynakça}

[1] Sarpkaya, T., Rajabi, F. 1980. Hydrodynamic drag on bottom-mounted smooth and rough cylinders in periodic flow. In Offshore Technology Conference. Offshore Technology Conference.

[2] Lundgren, H., Mathiesen, B., Gravesen, H. 1976. Wave loads on pipelines on the seafloor. In Proc., 1st Int. Conf. on Behaviour of Offshore Struct.(BOSS 76) (Vol. 1, pp. 236-247).

[3] Sumer, B. M., Jensen, B. L., Fredsøe, J. 1991. Effect of a plane boundary on oscillatory flow around a circular cylinder. Journal of Fluid Mechanics, 225, 271-300.
[4] Ballet, J. P., Hobbs, R. E. 1992. Asymmetric effects of prop imperfections on the upheaval buckling of pipelines. Thin-Walled Structures, 13(5), 355373.

[5] Xiaoyun, G., Fuping, G., Qun, P. 2001. Wave-soilpipe coupling effect on submarine pipeline onbottom stability. Acta Mechanica Sinica, 17(1), 86-96.

[6] Ong, M. C., Utnes, T., Holmedal, L. E., Myrhaug, D., Pettersen, B. 2010. Numerical simulation of flow around a circular cylinder close to a flat seabed at high Reynolds numbers using ak- $\varepsilon$ model. Coastal Engineering,57(10), 931-947.

[7] Draper, S., An, H., Cheng, L., White, D. J., Griffiths, T. 2015. Stability of subsea pipelines during large storms. Phil. Trans. R. Soc. A, 373(2033), 20140106.

[8] Gökkuş, Ü. 1995. Computer-Aided Design of Submarine Pipelines, Water Science Technology, 233-241.

[9] Varol, B. Y., Gökkuş, Ü. 2012 Düzenli Dalga Etkisinde ve Asılı Konumda Bulunan Deniz Boru Hattının Tesir Çizgisi Yöntemi Ile Analizi. Celal Bayar Üniversitesi Fen Bilimleri Dergisi, 8(2), 3142.

[10] Cokgör, S. Avcı, I. 2001. Hydrodynamic Forces on Partly Buried Tandem Twin Pipelines in Current, Ocean Engineering, 28:1349-1360.

[11] Lee, M. M. K. 1999. Strength, stress and fracture analyses of offshore tubular joints using finite elements. Journal of Constructional Steel Research, vol. 51, no. 3, pp. 265-286.

[12] CERC, 2002. Coastal Engineering Manual, Wave Mechanics, PartII, USA, Coastal Engineering Research Center, Vicksburg, MS, USA.

[13] Ergin, A. 2010. Coastal Engineering, Metu Press, Ankara, Turkey.

[14] Sorensen R. M. 2005, Basic Coastal Engineering, vol. 10, Springer Science \& Business Media, Berlin, Germany.

[15] Le Mehaute, B. 1976. Similitude in coastal engineering. Journal of the waterways, harbors and coastal engineering division, 102(3), 317335.

[16] Goda, Y. 2010. Random seas and design of maritime structures (Vol. 33). World Scientific Publishing Company.

[17] Keulegan, G. H., Carpenter, L. H. 1956. Forces on cylinders and plates in an oscillating fluid: US Department of Commerce. National Bureau of Standards.

[18] Yalçın, Y. Çevik, E. 2009. Kıyı Mühendisliği, Beta Basım A.Ş., İstanbul, 
[19] Wang E. Nelson T., 2002. Structural dynamic capabilities of ANSYS," in Proceedings of the ANSYS 2002 Conference, Pittsburg, PA, USA.

[20] Benra, F. K., Dohmen, H. J., Pei, J., Schuster, S., Wan, B. 2011. A comparison of one-way and twoway coupling methods for numerical analysis of fluid-structure interactions. Journal of applied mathematics. 